\title{
The Synthesis of an Aqueous Film Forming Foam Concentration and the Drainage Characteristic of the Foam
}

\author{
Xiujuan Wu, Changhai Li, Chuanwen Zhao, Youjie Sheng, Shouxiang Lu* \\ State Key Laboratory of Fire Science, University of Science and Technology of China, Hefei 230027, China
}

\begin{abstract}
Aqueous film forming foam (AFFF) is a very effective agent for firefighting hydrocarbon fuel fires. A study was conducted to develop a small-scale test for quantifying the drainage behavior of a synthesized AFFF formulation in accordance with the requirements of MIL-24385-F. The rate of drainage was measured to increase sharply to top firstly and then to decrease significantly. Furthermore, the results revealed that there was a critical moment when the drainage of solution slowed down suddenly, and when the most part of solution had drained from the foam.
\end{abstract}

Keywords-formulation; drain; firefighting foam; AFFF; foam mass

\section{INTRODUCTION}

Aqueous film forming foam (AFFF) is a very effective agent for firefighting liquid fuel fires[1]. Researches on AFFF focused primarily on testing the firefighting performance and chemical/physical properties of AFFF including extinguishment time, time to reignition or burnback time, drainage rate, evaporation rate and foam expansion ratio[2-8]. The drainage of solution from foam begins as soon as the foam is formed. Above all of these, drainage rate is an important parameter which is timedependent and is widely used to quantify the foam stability[9]. The rate of drainage has been previously [2, 4, $6,10-13]$ studied, and the rough drain rate of different foam formulations was obtained in these work, but none of these identifications was clearly enough. Furthermore, no quantitative explanation was found in these studies. As demonstrated through the study of Persson[4, 6, 11], different foam concentrates may result in different drainage rate. To characterize the drainage behavior of AFFF, a given AFFF concentrate was synthesized in this paper, and a modified small-scale test apparatus was developed to quantify the drainage characteristic the foam.

\section{EXPERIMENT}

\section{A. Foam concentrate}

Aqueous film forming foam solution which was used to generate foam was comprising of 3 percent or 6 percent of aqueous fluorochemical surfactant-containing concentrate by volume, and 97 percent and 94 percent water by volume, respectively[14-16]. The concentrate formulations exhibit excellent foaming characteristic, which enables the corresponding solution to produce a thick foam blanket that quickly extinguish the fire. The most important components in the AFFF concentrate are fluorocarbon surfactants, hydrocarbon surfactants, foam stabilizing compound, thickening material, burn-resistant agent, antifreezing agent and dissolvent. The components selected to synthesize AFFF concentrate in this paper were shown in Table I.

TABLE I. THE COMPONENTS IN THE SyNTHESIZED AFFF CONCENTRATE FORMULATION

\begin{tabular}{|l|c|c|}
\hline Category & Component & $\begin{array}{c}\text { Quality percentage } \\
\text { (\%) }\end{array}$ \\
\hline $\begin{array}{l}\text { fluorocarbon } \\
\text { surfactant }\end{array}$ & FC-001 & 5 \\
\hline $\begin{array}{l}\text { hydrocarbon } \\
\text { surfactant }\end{array}$ & SDS & 4 \\
\hline $\begin{array}{l}\text { foam } \\
\text { stabilizing } \\
\text { compound }\end{array}$ & Xanthan gum & \\
\hline $\begin{array}{l}\text { thickening } \\
\text { material }\end{array}$ & $\mathrm{C}_{8} \mathrm{H}_{18} \mathrm{O}_{3}$ & 0.2 \\
\hline $\begin{array}{l}\text { burn-resistant } \\
\text { agent. }\end{array}$ & $\left(\mathrm{HOCH}_{2}\right)_{2}$ & \\
\cline { 1 - 2 } solvent & $\mathrm{H}_{2} \mathrm{NCONH}_{2}$ & 4 \\
\hline $\begin{array}{l}\text { antifreezing } \\
\text { agent }\end{array}$ & Deionized water and others & 20 \\
\hline cosolvent & \multicolumn{2}{|c|}{5} \\
\hline others & & 61.8 \\
\hline
\end{tabular}

\section{B. Foam solution's surface tension measurement}

The AFFF solution was prepared by diluting the $3 \%$ of synthesized AFFF concentrate with the $97 \%$ of deionized water. The surface tension of the solution was measured by surface tension meter with maximum bubble pressure method. DHJF-4020 constant temperature mixing reaction bath was employed to keep the temperature of solution to be measured at $20^{\circ} \mathrm{C}$.

\section{Foam generation}

A repeatable compressed-air foam system was employed to generate the AFFF, as illustrated in Figure 1. The foam was produced by mixing compressed air with AFFF solution in the mixing chamber. 


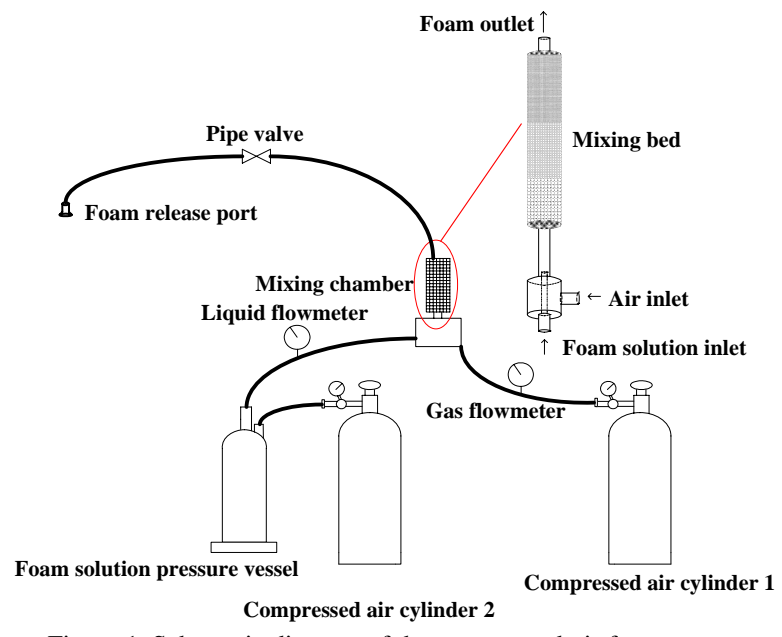

Figure 1. Schematic diagram of the compressed-air foam generator

\section{Determination of foam characteristics}

The foam expansion and $25 \%$ drainage time of consecutive batches of foam are the general parameters to used to characteristic the foam[9]. They could also be used to determine the reproducibility of the mechanically generated foam[2]. The definitions of both were proposed by NFPA 11[16]. According to this standard, expansion ratio is defined as the ratio of final foam volume to original foam solution volume. The $25 \%$ drainage time is defined as the the time in minutes that it takes for 25 percent of the total solution contained in the foam in the sample containers to drain. The expansion ratio and $25 \%$ drainage time of foam were determined emloying the method required in MIL-F-24385F[15].

The drainage rate of foam was determined using a small-scale test appratus which was modified on the basis of Lattimer's test pan[2]. The cylindrical shaped test pan was $230 \mathrm{~mm}$ in diameter and $150 \mathrm{~mm}$ high. The mass of the foam in the test pan was continuously monitored employing Load Cell \#1. The mass of the drained solution was continuously monitored employing Load Cell \#2. There were two major modifications in the test appratus. One modification was that the test pan was constructed of $3 \mathrm{~mm}$ thick quartz glass instead of the stainless steel. The transparency of the quartz glass enabled the height of the foam visible in the test pan during the drainage process. The other modification was that the drained solution was bleeded from the test pan employing the theory of communicating vessel, instead of using the electronically actuated solenoid valve.

\section{RESULTS AND DISCUSSION}

The physical property of AFFF solution synthesized in this research and the general characteristics of foam generated from the solution were shown in Table II. The values of these parameters confirmed to the requirements of MIL-F-24385F[15].
TABLE II. THE CHARACTERISTICS OF FOAM AND SOLUTION

\begin{tabular}{ll}
\hline Property & Value \\
\hline Surface tension $\left(\mathrm{mN} \cdot \mathrm{m}^{-1}\right)$ & 16.09 \\
Expansion ratio & 13.5 \\
$25 \%$ drainage time $(\mathrm{min})$ & 5.24 \\
\hline
\end{tabular}

The small-scale test used to quantify the drainage of AFFF was conducted at room temperature with no heating. The foam was continuously filled into the test pan for $74 \mathrm{~s}$ to keep the initial height of the foam in the test pan at $100 \mathrm{~mm}$. The mass of foam in the test pan and the mass of drained solution were monitored and the results were shown in Figure 2.

As shown in Figure 2, the mass of foam in the test pan increased sharply in the first stage, then decreased after this stage. The mass of drained solution increased with time. On account of the physical process of foam in the test pan, the plot was divided into three stages in Fig.2. The rising stage of the foam mass (denoted as A) was the filling stage of foam. The stage from $74 \mathrm{~s}$ to 291 s (denoted as B) was the major drainage stage of AFFF. After time was 291s (denoted as $\mathrm{C}$ ), the drainage of AFFF slowed down gradually. After the filling stage of foam, the mass balance of foam in the test pan and the drained solution was achieved.

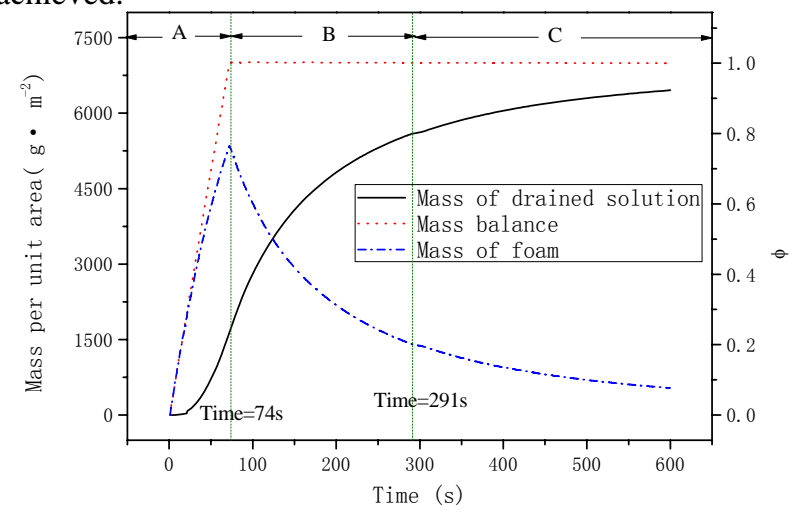

Figure 2. The mass of solution drained from AFFF with the initial height $\mathrm{h}=100 \mathrm{~mm}$

Note: $\phi$ was defined as the ratio of the mass of drained solution to the total mass of AFFF.

Figure 3 illustrated the drain rate of foam in the test pan. As shown in Fig.3, the rate of drainage increased sharply to top, then it decreased significantly after the highest point. The decrement turned from notable drop to increasingly smooth drop. Then a sudden drop turned up in the plot. After that, the rate of drainage picked up to the value before the sudden drop, and then it dropped increasingly slowly. The plot was divided into three same stages with in Figure 2. In stage A before time was $74 \mathrm{~s}$, the rise of rate of drainage may be caused by the filling process of the foam. On the one hand, the drained solution out of foam increased with increase of foam in the test pan. On the other hand, the filling of foam had an impact onto the liquid surface, 
resulting in more solution flowing out of the tube. After the filling stage, the liquid holdup in the the foam column was decreasing with solution draining out of the foam. On this basis, the drainage which is driven by gravity slowed down, as shown in stage B. It was worth noting that with decrease in rate of drainage, the pattern in which the drained solution flowed out of the tube turned from consecutive flow to discrete droplet at a critical moment when 80 percent of the solution had drained out of the foam. Therefore there was a sudden drop in the rate of drainage at the critical moment which was 291s. After that moment, the rate of drainage of foam picked up soon and then decreased smoothly, and its value was rather small due to the slow drainage.

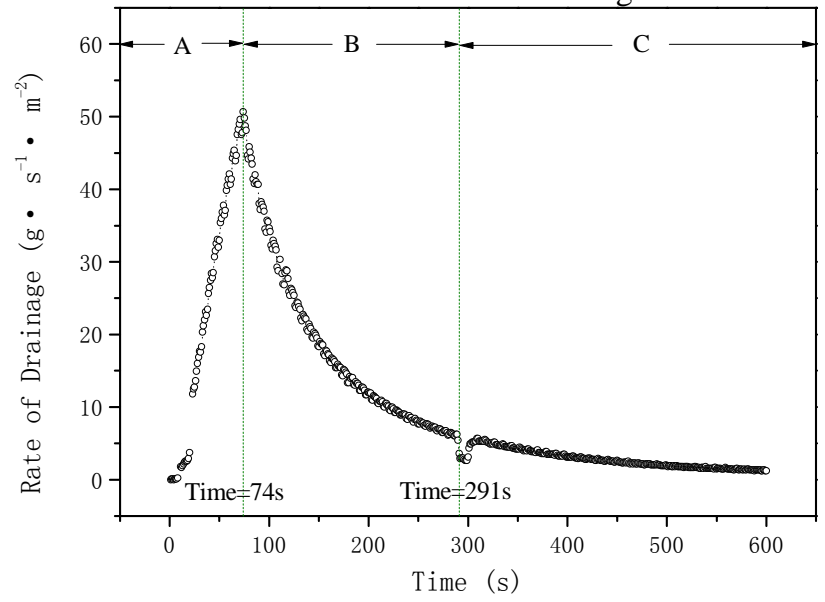

Figure 3. The rate of drainage of AFFF with the initial height $\mathrm{h}=100 \mathrm{~mm}$

\section{CONCLUSIONS}

A study was conducted to develop a small-scale test for quantifying the drainage behavior of an AFFF formulation synthesized in accordance with the requirements of MIL24385-F. The drain rate was measured to increased sharply to top then decreased significantly after the highest point. There was a critical moment when the drainage of solution slowed down suddenly, and when the most part of solution had drained from the foam.

\section{REFERENCES}

[1] T.R. L., Perterson, Full-scale Fire Modelling Test Studies of 'Light water' and Protein Type Foams, U.S. Naval Research Laboratory, Washington, DC.1967.
[2] L. BY, H. CP., S. JL., W. FW., The use of small-scale test data to characterize some aspects of fire fighting foam for suppression modeling, Fire Safety Journal, 38 pp. 117-146. 2003.

[3] L. AJ, R. MS, D. BZ, K. EM., Suppression performance comparison for aspirated, compressed-air and in suit chemically generated class B foams, Fire Technology. 2012.

[4] P. H, SP54 Report Fire Extinguishing Foams- Resistance Against Heat Radiation, Swedish National Testing and Research Institute.1992.

[5] M. SA, D. BZ, J. GJ, The Performance of Aged Aqueous Foams for Mitigation of Thermal Radiation, Developments in Chemical Engineering and Mineral Processing. 2000.

[6] I. S, P. H., Fire extinguishing foam- test mothod for heat exposure characterisation, Swedish National Testing and Research Institute.1997.

[7] W. B, M. T, B. C, B. Z, S. R, F. J, W. C, F. J, Extinguishment and Burnback Tests of Fluorinated and Fluorine-free Firefighting Foams with and without Film Formation, Suppression, Detection, and signaling Research and Applications- A Technical Working Conference(SUPDET), Florida.2011.

[8] C. Hanauska, B. Lattimer, Modeling of foam fire extinguishment, pp. 1-13. 2001.

[9] M. S.A., D. B.Z, Foam drainage,coarsening,and evaporation, in: Transport processes in bubbles, drops and particles, 2002, pp. 128162.

[10] M. S.A., B.Z. Dlugogorski, J. G.J., A Comparative Study of Drainage Characteristics of AFFF and FFFP Compressed-air Fire-fighting Foams, Fire Safety Journal, 37 pp. 21-52. 2002.

[11] H. Persson, M. Milovancevic, S.S.p.-o. forskningsinstitut, E.C. Measurements, T. Programme, FAIRFIRE Fire Fighting Foams: Small Scale Fire Test Procedure : Improvement of Drainage and Expansion Methodology, SP Swedish National Testing and Research Institute, Fire Technology, 1996.

[12] H. Persson, M. Milovancevic, S.S.p.-o. forskningsinstitut, E.C. Measurements, T. Programme, FAIRFIRE Fire Fighting Foams: Small Scale Fire Test Procedure : Improvement of Drainage and Expansion Methodology, SP Swedish National Testing and Research Institute, Fire Technology, 1996.

[13] P. B, FOAMSPEX: large scale foam application- modelling of foam spread and extinguishment, SP.2001.

[14] NFPA, Evaluating Aircraft Rescue and Fire-Fighting Foam Equipment, NFPA 412, pp. 1-14.1998.

[15] M. Specification, Fire extinguishing agent, aqueous film-forming foam (AFFF) liquid concentrate for fresh and sea water, MIL-F24385F, pp. 1-24.1992.

[16] NFPA, Standard for Low-,Medium-,and High-Expansion, NFPA 11, pp. 1-88.2010. 